\title{
A SELF DEFLATING CUFF FOR ARTERIAL COMPRESSION
}

\author{
Louis Fournier, M.D., F.R.C.P. (c) AND HenRu Desmeules, M.D., F.R.C.P.(c) ${ }^{\circ}$
}

ARTERIAL PUNCTURE Is a commonly used technique in anaesthesia and in many other specialties. As anaesthetists, we use this approach principally for blood gas analysis or for arterial pressure monitoring. This procedure is not without complications. ${ }^{1-3}$ The frequency of complications is related to the site selected for puncture. In our specialty, we use almost exclusively the radial, the brachial, or the femoral arteries. According to J. E. Mortensen, ${ }^{1}$ the radial artery is the safest to gain access to the arterial vascular pathway: he noted no major complications in over 120 punctures of this artery and only 2.5 per cent of minor complications were recorded. Pain at the site of puncture and ecchymosis were the most common complications. The formation of haematoma around the radial artery is in itself an innocuous complication. However, a haematoma might compel the operator to change the site of puncture if repeated blood gas analyses are required. If he selects the brachial artery, he must contend with a rate of major complications of around 8.9 per cent and for minor complications a rate of 42.2 per cent. ${ }^{1}$

The prevention of haematoma formation might thus be a factor in reducing the overall rate of complications following arterial punctures. To prevent bleeding after injury of the artery it is suggested that digital pressure be applied to the arterial puncture site for a period of about five minutes. This task is usually performed by an assistant who is not familiar with the importance of maintaining a constant pressure or is too busy to maintain this pressure for the prescribed period.

A simple apparatus has been devised to maintain this constant pressure for the prescribed period.

\section{Apparatus}

The apparatus consists of three simple parts (Figure 1). One is the familiar Tycos hand model anaeroid Spygmomanometer, the second element is a Baumanometer infant size blood pressure cuff, and the last component is a General Electric interval timer. Only two modifications are necessary to have a working apparatus. The first is to connect all the parts together with a $\mathbf{T}$ connector (Figure 1). The second modification is to affix three eyelets at the back of the timer through which is threaded a $\%$-inch rubber tube connected to the main tube coming from the cuff (Figure 2). The first two eyelets are fixed, but the third is movable, being affixed to the starting lever. When this lever is in the up position, the rubber tube is straight and the whole system is at atmospheric pressure. When the lever is depressed, the end of the rubber tube is kinked at the level of the third eyelet so that there is no leak in the system, permitting the inflation of the cuff (Figure 2).

- Department of Anaesthesia, Centre Hospitalier de l'Université Laval, Quebec City, Canada. Assistant Professors, Department of Anaesthesia, Laval University, Quebec City, Canada. 


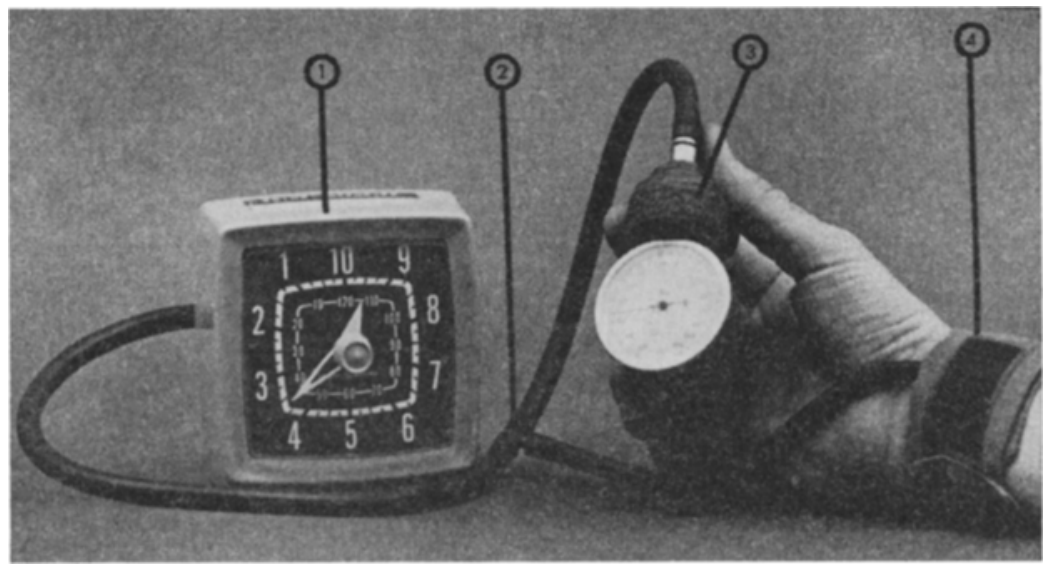

Figure 1. 1-Interval timer; 2-T-connector; 3-Tycos Sphygmomanometer; 4-Pressure cuff.

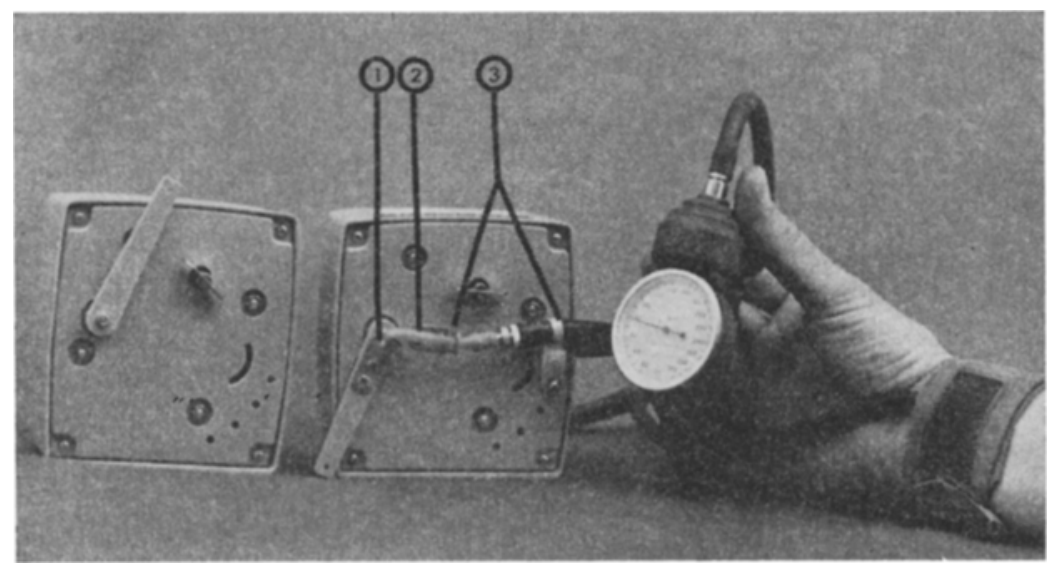

Figure 2. 1-Movable eyelet (kinking rubber tube); 2-Rubber tube; 3Fixcd eyelets.

At the end of the chosen period (five mimtes), the alarm rings, the lever goes up to its initial position and the cuff deflates.

This apparatus is very simple to use. When the needle is withdrawn from the artery, digital pressure is applied over the site of puncture with sterile gauze. With the free hand, the infant cuff is wrapped around the wrist or the elbow, as appropriate, and the interval timer is set for the desired period. Then, the lever is depressed and the cuff inflated to the chosen pressure. ${ }^{4,5}$ At the end of the compression period, the cuff deflates automatically.

This technique has been used after over 75 arterial punctures without any haematoma formation or other complications.. We have thus been able to puncture the same artery many times without any difficulties.

The authors are grateful to Mr. Ferdinand Lemieux, Electronic Technician, for his help in assembling this instrumentation. 


\section{RÉSUMÉ}

Nous avons utilisé un appareil d'une grande simplicité pour faire la compression d'une artère à la suite d'une ponction artérielle. Cet appareil permet de maintenir la compression pour un temps choisi et se dégonfle automatiquement au bout de cet intervalle.

\section{REFERENCES}

1. Mortensen, J. D. Clinical Sequelae from Arterial Needle Puncture, Cannulation and Incision. Circulation, 35: 1118 (1967).

2. Ertxsen, H. C. \& Sorensen, H. R. Arterial Injuries. Acta Med. Scandinav. 135: 133 (1969).

3. Bergentz, M. D.; Hansson, L. O. \& Norback, B. Surgical Management of Complications to Arterial Puncture. Annals of Surgery, 164: 1021 (1966).

4. GardnER, W. J. \& Storer, J. The use of the G-Suit in control of intra-abdominal bleeding. Surg. Gynec. \& Obstet., 123: 792 (1966).

5. Wangensteen, S. L.; LuDEwiG, R. M.; Cox, J. M.; \& Lynk, J. N. The Effect of External Counterpressure on Arterial Bleeding. Surgery, 64: 922 (1968). 